\title{
BMJ Open Risk perception of sexually transmitted infections and HIV in Nigerian commercial sex workers in Barcelona: a qualitative study
}

\author{
Núria Coma Auli, ${ }^{1}$ Cília Mejía-Lancheros, ${ }^{2}$ Anna Berenguera, ${ }^{3,4}$ \\ Enriqueta Pujol-Ribera ${ }^{3,4}$
}

To cite: Coma Auli N, MejíaLancheros C, Berenguera A, et al. Risk perception of sexually transmitted infections and HIV in Nigerian commercial sex workers in Barcelona: a qualitative study. BMJ Open 2015:5:e006928.

doi:10.1136/bmjopen-2014006928

- Prepublication history for this paper is available online. To view these files please visit the journal online (http://dx.doi.org/10.1136/ bmjopen-2014-006928).

Received 15 October 2014 Revised 15 May 2015 Accepted 22 May 2015

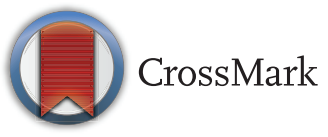

${ }^{1}$ Unitat de medicina tropical i salut internacional Drassanes-Vall d'Hebron, Institut Català de la Salut, Barcelona, Spain

${ }^{2}$ Department of Paediatrics, Obstetrics, Gynaecology and Preventive Medicine, Universitat Autònoma de Barcelona, Barcelona, Spain ${ }^{3}$ Institut d'Investigació en Atenció Primària (IDIAP Jordi Gol), Barcelona, Spain

${ }^{4}$ Investigador Associat de la Universitat Autònoma de Barcelona, Bellaterra (Cerdanyola del Vallès), Spain

Correspondence to Enriqueta Pujol-Ribera; epujol@idiapjgol.org

\section{ABSTRACT}

Objective: This study aimed to determine in detail the risk perception of sexually transmitted infections (STIs) and HIV, and the contextual circumstances, in Nigerian commercial sex workers (CSWs) in Barcelona.

Design: A qualitative study with a phenomenological approach.

Setting: Raval area in Barcelona.

Participants: 8 CSWs working in Barcelona.

Methods: A phenomenological study was carried out with Nigerian CSWs in Barcelona. Sampling was theoretical, taking into account: different age ranges; women with and without a partner; women with and without children; and women participating or not in STI/ HIV-prevention workshops. Information was obtained by means of eight semistructured individual interviews. An interpretative content analysis was conducted by four analysts.

Results: Illegal immigrant status, educational level, financial situation and work, and cultural context had mixed effects on CSW knowledge of, exposure to, and prevention and treatment of STI and HIV. CSWs were aware of the higher risk of STI associated with their occupation. They identified condoms as the best preventive method and used them during intercourse with clients. They also implemented other preventive behaviours such as personal hygiene after intercourse. Control of sexual services provided, health education and healthcare services had a positive effect on decreasing exposure and better management of STI/HIV.

Conclusions: Nigerian CSWs are a vulnerable group because of their poor socioeconomic status. The perception of risk in this group and their preventive behaviours are based on personal determinants, beliefs and experiences from their home country and influences from the host country. Interventions aimed at CSWs must address knowledge gaps, risk behaviours and structural elements.

\section{INTRODUCTION}

According to the Joint United Nations Programme on HIV/AIDS (UNAIDS),

\section{Strengths and limitations of this study}

- This study contributes new data on the perception of contracting and transmitting sexually transmitted infection (STI) among Nigerian commercial sex workers (CSWs), a highly visible group in the Raval area of Barcelona.

- From this study, we can determine the social environment and understand the risk perceptions of these high-risk Nigerian CSWs concerning STIS/HIV, in order to design more suitable, acceptable, sustainable and effective educational and preventive interventions.

- The results should significantly improve multisectoral services aimed at this group and increase the control of STIS/HIV, which are a great public health concern with a large social component.

- Recruitment of volunteers to participate in the study was difficult because CSWs are a stigmatised population group.

- The discourse analysis planned in the study protocol could not be carried out for the following reasons: (i) it was not possible to obtain triangular groups, thus it was not possible to capture the common meaning among participants and rebuild social entities from analysis of these interactions; (ii) the language of the participants was not rich enough to explore different discursive axes.

approximately 32.2-38.8 million people were infected with HIV in 2012; of these, approximately 3.4 million were new cases. Commercial sex workers (CSWs) are among the most vulnerable groups to contracting HIV. Indeed, they are 13.5 times more likely to live with HIV than non-CSW women. The United Nations programme indicates that efforts to reduce transmission of HIV in CSWs have been insufficient, as reflected by the high prevalence in this group. In Sub-Saharan Africa, the prevalence of HIV in CSWs is estimated at $36.9 \%$, much higher than in other regions of the world. $^{2}$ 
A systematic review by Platt $e t a l^{2}$ found a higher prevalence of sexually transmitted infections (STIs) in immigrant CSWs. In addition, immigrant CSWs from Africa have a higher prevalence of HIV infection than CSWs from other regions, in accordance with the high prevalence of HIV/AIDS in many African countries.

Sex work is mainly associated with adverse socioeconomic conditions. CSWs in the main Spanish cities originate from different countries. A 2004 study by Belza et $a \vec{l}$ showed that, in Spain, over $70 \%$ of CSWs were immigrants. In Barcelona in 2004, a study showed that $67 \%$ of CSWs originated from Sub-Saharan Africa, Latin America and Eastern Europe. ${ }^{4}$

Whereas some studies show that CSWs commonly use condoms during sexual intercourse with clients, they rarely do so when they engage in non-commercial sex as a sign of 'a truly intimate relationship'. ${ }^{5}$ The success of programmes to reduce risk of HIV infection has varied in different settings; whereas in Benin there was greater use of protection and a significant decrease in the prevalence of STI/HIV infection in CSWs was achieved, ${ }^{6-9}$ in Mozambique and other countries condoms were not systematically used. ${ }^{10}{ }^{11}$ In a study carried out in Cambodia, Maher $e t a l^{12}$ asserted that risk perception is socially constructed and specific for each context. In consequence, prevention programmes must take into account all interpersonal, social and cultural factors and emphasise that every relationship carries a risk. ${ }^{12}$ They conclude that more research is needed before translating the results into guidelines and more effective prevention programmes. ${ }^{5} 10$

The first articles on STI risk in Nigeria were published in the 1970s and 1980s, before the explosion of the HIV epidemic. Studies considered the following risk factors: polygamy, promiscuity and sex work, together with increased freedom of women, increased internal migration of young people in search of job opportunities, growth of cities, increase in casual intercourse, more extensive use of non-barrier contraceptives, lack of a good public health system, and inadequacy of diagnosis and treatments. In addition, the social stigma and feelings of shame prevented many young people from seeking treatment for STI. Overall, these studies highlighted the need for health education in young people and groups at risk and for adequate treatment of cases. ${ }^{13-15}$ In Nigeria it is estimated that CSWs account for $\sim 20 \%$ of new infections by HIV. ${ }^{16}$

In a study carried out in Nigeria in 2012, Lawan et $a l^{17}$ found that most CSWs are aware that unprotected intercourse and multiple sexual partners are the main risk factors for STI and HIV/AIDS. The study concludes that increased risk perception is related to older age and higher educational level rather than to marital status or length of time as a CSW. Although most CSWs identified the condom as the best method of preventing STI, up to $25 \%$ were not aware of any method of prevention, and $50 \%$ practised unprotected sex despite active STI symptoms. They explained that CSWs are stigmatised and they felt marginalised and criminalised by society.
Consequently, they could not readily access social and health services.

It has been shown that implementation of adequate policies of health promotion and prevention programmes in population groups at risk of STI/HIV, such as CSWs, is essential and cost effective for changing behaviours and decreasing prevalence and incidence. 161819

There are no data on the risk perception of STI/HIV in Nigerian CSWs in Spain. Nigerian CSWs are highly visible in the Raval district, where many attend services offered by non-governmental organisations (NGO). ${ }^{4}$ The Raval district is a neighbourhood in the historical centre of Barcelona. ${ }^{20-22}$ Over the last few decades, it has experienced significant sociodemographic and cultural change. From a population that was mainly local, it has changed so that a large percentage of its current inhabitants $(\sim 56.5 \%)$ are immigrants from Northern Africa and South East Asia. Sex workers on the streets of the Raval are increasingly becoming the focus of attention. Indeed, sex work here is mainly practised by immigrants, in particular from South America, Sub-Saharan Africa and Eastern Europe. Although it is forbidden by Catalan law, commercial sex work operates mainly on the streets.

The main goal of our study was to analyse understanding, attitudes and behaviour related to perception of the risk of contracting and transmitting STI/HIV in Nigerian CSWs in the Raval district of Barcelona.

\section{METHODS}

Design

We carried out a qualitative study based on a phenomenological perspective to identify and interpret discourses. The study aimed to understand and interpret what the risk of contracting and transmitting these infections meant for this population group as a result of their experiences, taking into account socioeconomic, cultural and political factors, availability of social and health services, and social integration. ${ }^{23}$

\section{Sampling and strategy of participant selection}

Purposeful and theoretical sampling based on an a priori definition of participants' characteristics was carried out to obtain optimal variety and discursive wealth. ${ }^{24}$ Nigerian CSWs over 18 years old (legal age of adulthood in Spain) working in Barcelona were selected. We took the following criteria into account: different age ranges, with and without partner, with and without children, and participating or not in educational activities aimed to increase awareness and prevention of STI/HIV. We also considered the length of time that participants had been practising commercial sex work and residing in Spain (table 1).

Potential participants were approached by means of the following. (1) Successive visits were made to the streets of the Raval district by the research team, who explained the study's aim to the target population and 
Table 1 Sociodemographic characteristics of the participants

\begin{tabular}{|c|c|c|c|c|c|c|c|}
\hline Name & Age & Partner & Children & Workshops* & Time as a CSW† & Education‡ & Arrival§ \\
\hline Anita & 23 & Yes & No & No & 2 years on and off & १ & 2010 \\
\hline Joy & 27 & No & Yes & No & 2 years & Primary & 2003 \\
\hline Monica & 32 & No & No & Yes & 5 years & None & П \\
\hline Rosa & 40 & Yes & Yes & No & 8 years & Primary & 2005 \\
\hline Happy & 32 & No & Yes & Yes & 3 years (not currently) & Primary & 2006 \\
\hline Osas & 33 & Yes & Yes & Yes & 5 years & Secondary & 2004 \\
\hline Jennifer & 24 & No & Yes & No & 1 month & Primary & ๆ \\
\hline Silvia & 40 & No & Yes & Yes & 2 years (not currently) & University & 2007 \\
\hline \multicolumn{8}{|c|}{$\begin{array}{l}\text { *Health courses or job placement courses. } \\
\text { †Length of time as a CSW. } \\
\text { †Educational level (none; primary; secondary; university). } \\
\text { §Year they arrived in Catalonia. } \\
\text { ๆNot available. } \\
\text { CSW, commercial sex worker. }\end{array}$} \\
\hline
\end{tabular}

left a flyer with contact details in case anyone should want to take part in the study. Nobody called. (2) Two meetings with the study population were organised with the collaboration of the NGO 'Àmbit DONA', where the project aims were explained. Nobody wanted to participate without a financial incentive. (3) The Centre for Prevention and Control of Sexually Transmitted Infections at Drassanes was actively involved in approaching potential participants among users of the unit. (4) Finally, social workers from the NGO 'El lloc de la dona' were also engaged in recruitment of informants.

\section{Techniques to generate information}

Twenty-one Nigerian CSWs were invited to participate. Nine refused when they knew they would not be paid and four because they were not interested in the study. Eight semistructured individual interviews were carried out with the eight participant Nigerian CSWs, and data saturation was reached with the information obtained. ${ }^{25}$ Individual interviews provided a safer environment for study participants, thus encouraging spontaneous responses. Triangular groups ${ }^{26}$ were planned but not implemented because of the difficulty of accessing the study population.

Once women agreed to take part in the study, researchers explained its purpose and the confidentiality of the data collected. Participants were asked to sign written informed consent forms in English or Spanish for the interview to be recorded and for the publication of the study. Individual interviews lasted $\sim 30 \mathrm{~min}$ and were audio-recorded. The interviews were conducted by the study researchers, five in Spanish and three in English.

\section{Setting and data collection methods}

Data collection took place during 2013 in Barcelona. Interviews were held in a primary healthcare centre with an interviewer and an observer. The main topics explored were: (1) knowledge of STI/HIV/AIDS; (2) behaviour and risk perception; (3) socioeconomic, political and cultural aspects related to working as a
CSW (further details in box 1 of the study protocol which can be found in Coma $e t a l^{27}$ ).

\section{Data analysis}

We conducted an interpretative content analysis. ${ }^{28}$ The discourse analysis planned in the study protocol could not be carried out for the following reasons: (i) it was not possible to obtain triangular groups, thus it was not possible to capture the common meaning among participants and rebuild social entities from the analysis of these interactions; (ii) the language of the participants was not rich enough to explore different discursive axes.

All sessions were recorded and transcribed verbatim and systematically by members of the research team and trained external personnel. ${ }^{29}$ After successive readings of the transcriptions, researchers reached some preanalytical intuitions. Next, four researchers undertook the following analytical steps: (a) identification of the relevant subjects and texts; (b) fragmentation of the text into units of meaning; (c) text codification with emerging codes from the data; (d) creation of categories by grouping the codes by the criterion of analogy; (e) analysis of each category; (f) elaboration of a new text with the results. These results were subsequently discussed with all the research team until a consensus was reached.

Three analytical procedures were performed to improve rigor: ${ }^{30}$ (a) triangulation of data analysis by four researchers; (b) the main findings were compared with the original data; (c) the research team sent the results to a participant and to a key informant as part of the validation process. No objections were made. This validation process added elements to the analysis and allowed consensus regarding interpretation of the results.

\section{Ethical aspects}

This study was conducted according to the Helsinki Declaration and Good Clinical Research Practice. Participants signed informed consent forms at the beginning of each interview. A name made up by each participant guaranteed confidentiality and anonymity of the 
data. This name was used to identify the transcriptions and the selected verbatim transcripts. The project was approved by the Clinical Research Ethics Committee of the Primary Health Care University Research Institute, IDIAP Jordi Gol (P12/038).

\section{RESULTS}

The results are presented according to the categories that originated from analysis of personal health determinants, occupational determinants and social influences in the host country (figure 1) and its interactions between these categories (figure 2). Table 2 shows the CSW quotations.

\section{Personal health determinants}

\section{Socioeconomic situation in the country of origin}

\section{and migration process}

Participants explained that in their home country they lived with their families, carrying out housework and maybe also some sewing and selling in the market. However, these activities were not productive enough financially and no expectations of improvement existed. Although their social and family life in their countries of origin was good, they mentioned lack of education and work opportunities as the main reasons to emigrate to Europe. One informant explained that a friend persuaded her to join her because she had improved her economic status, and another explained that she came to Europe with the assistance of somebody to whom she was heavily indebted.
Socioeconomic situation in the host country

\section{and personal expectations}

The participants arrived in Spain without money, family or a job, and they are still illegal residents. No participant admitted to being HIV positive. They emigrated under the assumption that they would have opportunities for a better life in Europe. Participants feel vulnerable, alone and without socioeconomic support. In consequence, they believe that their only way to survive is commercial sex work. Most explain that they live in very poor conditions and are poorly integrated into society, which further hinders their possibilities of finding a proper job and proper housing.

The need to pay off acquired debts, the costs of everyday living, and family burdens, in Barcelona and in Nigeria, emerged as justifications for their trade.

Most of them claimed that they were looking for, and would like to have, some other occupation such as cleaning, sewing, taking care of the elderly, having a fruit stall or a bar. Some of them had even finished training that would allow them to improve their situation. However, they could not do anything without a residence permit.

Some of them would like to marry and have children and a more conventional lifestyle.

\section{Previous experience in Nigeria and Nigerian opinion on sex work}

The participants described differences between their life and social context in their home country and in Barcelona.

None of them had been a CSW in Nigeria. They explained that sex work is not acceptable in Nigeria,

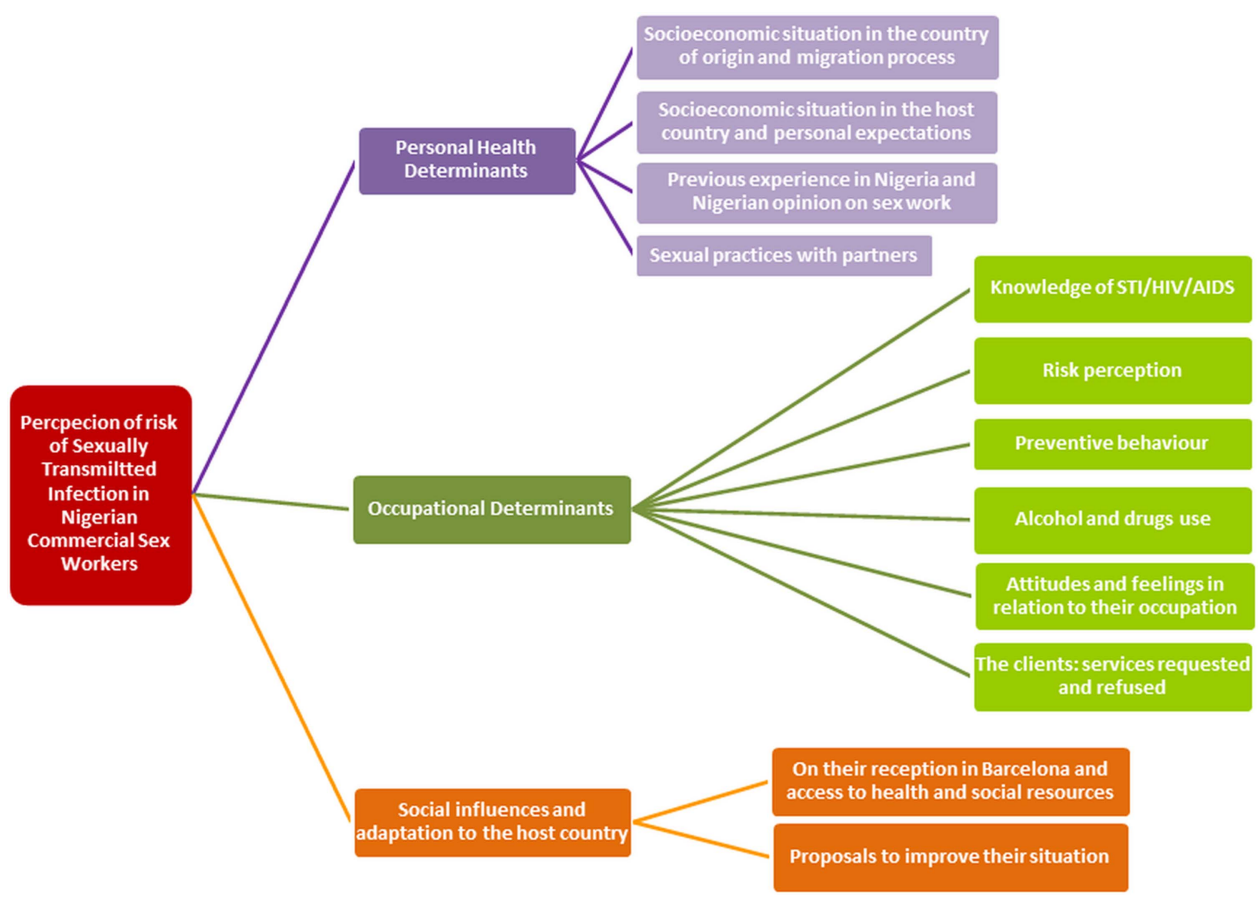

Figure 1 Classification of results according to categories and subcategories of the analysis. 
Figure 2 Circumstances related to preventive behaviours in Nigerian commercial sex workers in Barcelona.

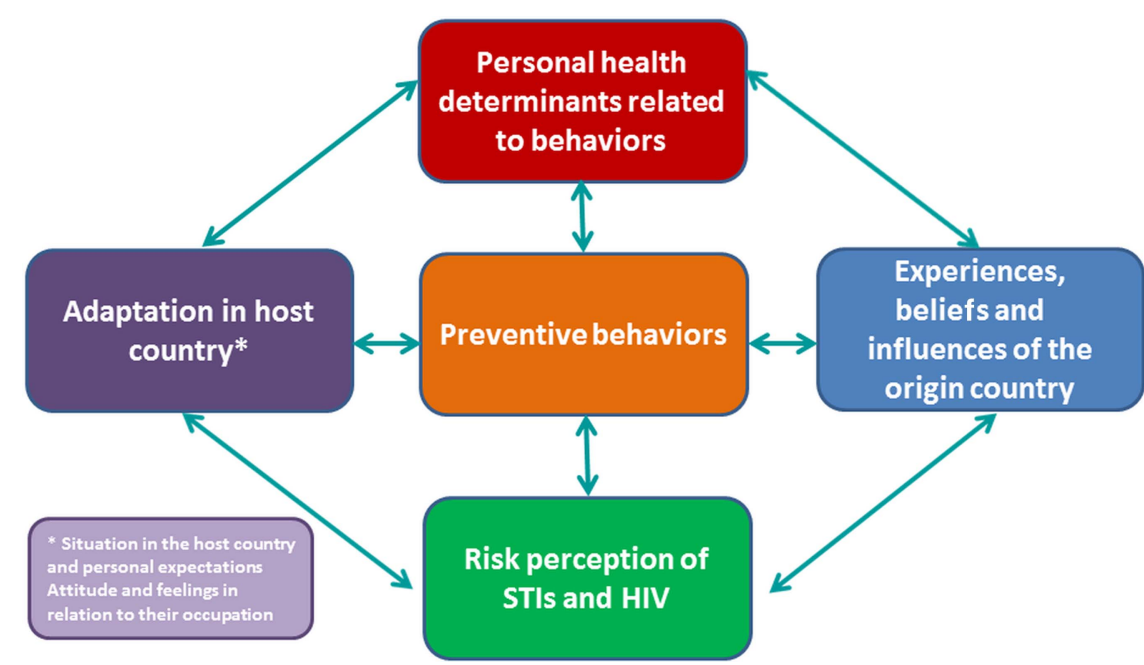

where CSWs work in hotels and need to hide. They believed that being a CSW is much more accepted in Europe.

The discourses also mention the taboo with regard to homosexuality in Nigeria. Many consider it a forbidden topic and many people are against it.

\section{Sexual practices with partners}

With regard to sexual practices, they generally refused oral and anal sex; they did not like it and did not want or could not practise it.

They preferred not to use a condom with their partners. Some used one with their partner and some asked their partner to be tested for STI. If the partner refused, they used condoms.

\section{Occupational determinants \\ Knowledge of STI/HIV/AIDS}

Most participants had been told of STI/HIV/AIDS before becoming a CSW; some mentioned receiving sex education at school in their home country. Some had received information from NGOs and other institutions. The best known diseases were syphilis, gonorrhoea and HIV. It is important to highlight that some participants did not know anything about HIV and that one of them thought cancer was an STI.

Only the participant with the highest educational level understood all aspects related to these infections. They defined STI/HIV/AIDS as diseases acquired through intercourse without a condom, promiscuity, sharing needles and sharp, cutting objects, sexual relations with scruffy looking people, and when there is uncertainty about the health of the partner. In addition, they related STI to the use of dirty toilets, eating food in suboptimal conditions, and going for diagnosis and starting treatment too late.

\section{Perception of risk of contracting STI/HIV/AIDS}

All participants claimed to know that their trade makes them vulnerable to STI/HIV/AIDS and they wanted to protect themselves. They identified their clients as a risk, since they ignored whether their clients had any type of disease, including STI/HIV/AIDS.

They claimed that they could not always wash after intercourse and knew that, when a condom breaks, they are directly exposed. This group of CSWs did not consider themselves a risk to their clients and were not concerned about protecting them. They all claimed to use condoms during intercourse with clients.

In contrast, they considered themselves a risk factor for their partners and also considered their partners to be a potential source of infection. Their main concern was at the start of a new relationship, when some claimed they went to the health centre to have blood tests and demanded that their partners have them too to be able to have unprotected sex. In general, most of them were much less cautious when the relationship was more established. Whereas some explained that they used a condom with their partner, others admitted that they did not use condoms even when they knew that their partner had other sexual contacts.

They admitted to fears about attending a health centre when a condom broke, fear of contagion, fear of what the health professionals would say to them in the health centre, and fear of the results of the tests. They usually went for tests, but feared returning to obtain the results.

\section{Preventive behaviour}

Most of them knew that a condom is the most effective prevention. All of them claimed to use condoms during intercourse with clients.

After intercourse with clients, they tried to perform activities they considered preventive, such as washing with soap and water, although one of them mentioned that soap was bad for infections. They also used toilet paper and saliva when they could not wash better. They mentioned products for feminine hygiene from their home country. Some explained that they took medicines (antibiotics) as prevention. They also went to the doctor for check-ups and for blood tests. 
Personal health determinants

Occupational determinants
Socioeconomic situation in the country of "When I was in my country...only my husband worked.... when I was pregnant...he died....so I origin and migration process

Situation in the host country and personal expectations

Previous experience in Nigeria and Nigerian opinion on sex work

Sexual practices with partners had no help....no money... I wanted to leave my country..." (Osas)

"...here is better than my country. In the country there is not job, not job. One day, one day...

Well, in my country I did not go to school. If I studied in my country...like college, and... finishing secondary school ... here l'm going to have very good life, much easy to find work. But I not have study, cannot read, only a little....in my country, if you have no money cannot go to school..."(Happy)

"we do it because someone brought us here"; "we need to pay that person"; "so, you must do it, because the money they ask us to pay is big money" (Anita)

"... Well... my friend was in Europe... she persuaded me to come... she arrived home with lots of money, she built a house... a car...she said that in Europe plenty...I sold everything I had from working and...look what I found here." (Silvia).

"...No, in this place, I cannot rent a flat... because of the money... I have to take a room for somebody..."(Jennifer)

"Of course, when I have my residence, I look for job, because I have lots of courses,

diplomas, and look for job". (Mònica)

"My country, I did sewing in my country". (Happy)

"In my country I didn't do it; I didn't working before.... My country.... I helped my mother... to sell in the market" (Mònica)

"...my life have changed a lot, big time... When I was in my country I was going to the school, and don't do this kind of job. I don't sleep with men because of the money, but coming to Europe has changed lot time, big time..." (Anita)

"mmm... yes, because here is more open, in my country... it exists but... it is like secret... you understand me? Here is like a trade... not in my country... if you are like this... people do not respect you. But here it is your job...you can do as you please..." (Silvia)

"....in my country... if some people work in a hotel, but here you can work in a hotel and can work in the street..." (Mònica)

"I do not fuck behind, in my country we do not talk about it... there man with woman, woman with man, but not woman with woman, man with man, but it is never mentioned..." (Happy)

"No, with my boyfriend I don't use protection." (Anita)

"If I have boyfriend... before you use the skin with him... I said let first go for test, so if we are clean...then you can use the skin together... Only visit not, If say not, we use condom for act because I don't know if are sickness..." (Jennifer)

"... with my partner I fuck always without condom" (Joy)

"AIDS and cancer are disease, disease.... For...me...AIDS worse". (Joy)

"HIV cannot be cured. Syphilis and gonorrhoea yes." (Happy)

"Diseases, infections through the sex, you can take infections through the sex..., through the toilets and through... maybe... the blood..." (Jennifer)

"When...you fuck, no rubber, you get AIDS. When you also suck you get disease, also when you have dirty hands and you touch your... ... sex... you also get disease and when you suck natural you also catch the disease." (Joy)

Continued you can get something for doing... so you can give money..."(Jennifer) 
Perception of risk of contracting STI/HIV/AIDS

Preventive behaviour

Alcohol and drugs use g

Attitude and feelings in relation to their occupation

"[yaa], there are a lot of risk in this job, very, very...a lot of risk and most people don't know... And...just people they have these diseases they don't tell you and still up working." (Anita) "This work it's very dangerous, it's not good... Because maybe they need money... or not job, maybe they are looking for job... still can let me go for that... it's very dangerous, you have to protect yourself..." (Jennifer)

"...there is also other people... that are not my partner... then you have to use the condom with your partner and elsewhere. Then... better for him and you." (Silvia)

"Mmmm... you know in the street I use condom, you have to be careful so that the condom don't blow... yes..." (Jennifer)

"Yes, yes... If works in the street or in bed with other sometimes they don't know many other girls fear going to hospital." (Osas)

"Yes... with condom... you have to make with condom ... otherwise... no... business...".

(Silvia)

"First shower and when enter flat, go to bathroom to shower and once a week I wash in a...I buy in [mentions supermarket]... one liquid." (Osas)

"Yes, if it's itchy... you can put... antibiotics... to prevent also ... Yes, yes... gels also...". (Silvia)

"I use Kleenex in the streets, I use Kleenex...to clean the condom, to clean myself, maybe for clean, when I finish to use condom if there are not water to wash yourself, .....maybe in the weekend, you can use hot water... hot water.... with "roc", you take a little and put it in hot water... and with towel... and you sit in the bucket and you, cover yourself with towel... you sit over the heat...the vapour... 10 or 15 minutes with hot water ... you clean... and everything gets out" (Mònica)

"I... drink whiskey ... don't know....I think it happens, it makes me vomit, I find it disgusting... yes disgusting... I have taken ampicillin, all to clean, and I have taken a liquid to clean ... it is called... "ditoy", it is for the shower, also my vagina... it contains gas..." (Mònica)

"No, I don't take drugs." (Anita)

"In my family never woman can smoke, if you do your family considers bad person..." (Happy)

"no,..no... I drink sometimes, maybe before I leave home I drink coffee because I don't want sleep, and sometimes I drink Red Bull... that's it... because of sleep" (Mònica)

"it's very dangerous, you have to protect yourself". (Jennifer)

"Yes... because need money to eat, to pay the rent, does not have a job, papers... What can I do? But I don't like it, if I don't want to see a street, I think, I don't like to touch man, it is not right....." (Happy)

"It's not something you are proud of it... I want to stop it" (Anita)

"... for disease, also shame because have an older child, asks "mum, where are you going now?"'“ (Osas)

"...better work in clubs than on the streets....but I don't have documents. I can't" (Osas)

"...me...I don't like the street, I have to survive on the streets ....that is very hard" (Joy) "...I don't like do this..., I don't want to work on the street... How can I do to eat?" (Happy) 


\begin{tabular}{|c|c|c|}
\hline & $\begin{array}{l}\text { The clients: sexual practices requested } \\
\text { and refused }\end{array}$ & $\begin{array}{l}\text { "Yes, I refuse the anal sex, I don't do it" (Anita) } \\
\text { "clients want to suck without condom... but there are others who want nothing without } \\
\text { condom... many tourists use condom." (Joy) } \\
\text { "they act as if you were not human... because he pays thinks that you are going to do } \\
\text { anything ..." (Silvia) } \\
\text { "yes, sometimes...people request without condom... without condom...." (Mònica) } \\
\text { "with client... he tries want to suck without condom" (Joy) } \\
\text { "Maybe, some want to have sex with my anus...but I don't do that" (Mònica) } \\
\text { "Yes, and some ask you if they can fuck you in your ass...YYes, but I can't do that, I don't do } \\
\text { that.... Yes, I refused the anal sex, I don't do it." (Anita) }\end{array}$ \\
\hline \multirow[t]{2}{*}{$\begin{array}{l}\text { Social influences and } \\
\text { adaptation in the host country }\end{array}$} & $\begin{array}{l}\text { On their reception and the health and } \\
\text { social resources in Catalonia }\end{array}$ & $\begin{array}{l}\text { "Mmm... yes, once. It was last year, in Ramblas. I was caught by the police... they accused } \\
\text { me of stilling...but nothing like that..." (Anita) } \\
\text { "...here experience, here adult courses, here I have learned a lot. But now there is no work" } \\
\text { (Rosa) } \\
\text { "Here is better than my country... I'm doing a course...for...how to get job... how to do the } \\
\text { cleaning... everything..." (Jennifer) }\end{array}$ \\
\hline & Proposals to improve their situation & $\begin{array}{l}\text { "ahhh... I like if they can help us, maybe help some of us leave the streets, maybe put them } \\
\text { in the school, going to school, from then they can get a job, many with they can assist them. } \\
\text { Maybe they stop doing the job because is no one of them than like doing it. ...Stop it." (Anita) } \\
\text { "I want the residency...They should sort out the things of the people that work...in the street, } \\
\text { they must have rights and be able to be sick...Now more girls take to the streets...more... } \\
\text { because there is no work, because of the crisis there are more girls in the street. They even } \\
\text { leave the children on their own at home to go to work. Now there are many young..." (Silvia) } \\
\text { "I: How could you imagine your future in } 3 \text { years? } \\
\text { I imagine maybe... sometimes... it can be better, working, my baby going to the school... and } \\
\text { everything..." (Jennifer) }\end{array}$ \\
\hline
\end{tabular}


The prevention practices after intercourse with clients are related to the knowledge acquired in their home countries, within their trade, and in the health courses they attended.

\section{Alcohol and drug use}

All denied drug use, either at work or home. Most did not drink alcohol during work. One claimed not to accept drunken clients. Some admitted to smoking, and one explained that she drank coffee or Red Bull before leaving her house to avoid falling asleep.

\section{Attitudes and feelings about their occupation}

Most participants considered they had a risky occupation in relation to contracting STI and personal safety. However, they claimed that they never worked in conditions that they could not control, such as with clients under the effect of alcohol and drugs, in order to avoid dangerous situations.

Most participants explained that nobody forced them to work on the streets and that they did not end up in Barcelona through deception. Some started other jobs, but lost them due to the financial crisis and resorted to prostitution to survive. None of them liked being a CSW and they considered it shameful. They all claimed that they would change occupation as soon as they could.

\section{The clients: sexual practices requested and refused}

The differences between clients meant that CSWs must negotiate preventive measures. The 'tourist' clients always demanded and used condoms and they paid more for the service. The local clients, of different nationalities, often wanted intercourse without a condom and they offered more money if the CSW accepted. However, they refused in order to protect themselves from STI.

The participants complained that clients often did not respect them and thought that, because they paid, they could do as they pleased.

Most participants exerted control over the services they provided. Many clients asked for unprotected intercourse and oral sex, to touch the genitals with their hands, and to suck their breasts. The CSWs claimed to refuse these practices.

The most commonly refused practice was anal sex. All the participants disliked it, although they did not elaborate further. They also did not accept more than one client at a time.

The participants were not specific in relation to earnings, but one mentioned 20 euros and another said that sometimes she only got 5 euros for a service that included sexual intercourse.

\section{Social influences and adaptation in the host country}

On their reception and the health and social resources

in Catalonia

The participants explained that they had access to and used the health services. Sometimes the visit was related to their occupation, in which case they might consult about abdominal pain, vaginal itching or vaginal discharge, and might even request blood tests for the diagnosis of STIs. Other times they needed health services for other reasons. They had also contacted the social services, mainly to obtain assistance for their children. They said that they had encountered no problems with getting their children admitted to state schools.

Most of them had had encounters with the police: some had been accused of stealing; some had been asked for documentation; and some had been fined for working on the street. Half of the participants had spent at least one night in jail.

The participants received social assistance and different courses organised by NGOs on health, Spanish and professional training.

Despite being illegal immigrants, most participants claimed that life in Barcelona was better than in their home country. Some explained that they were not going back, despite having families and sometimes children there. They believed in a better future, with a better job and a better life for their children.

\section{Proposals to improve their situation}

Proposals to improve focused on obtaining legal residency status, which they considered essential for obtaining a better job, earning more money and achieving a better future for themselves and their families. All participants asked institutions and politicians for access to more training opportunities and better jobs.

\section{DISCUSSION}

This study determines in detail perceptions of risk of contracting and transmitting STI/HIV in a group of Nigerian CSWs in the Raval district of Barcelona.

The profile of the study participants reflects the diversity in age (20-40 years) and presence or absence of a partner and children. On the other hand, most of the participants were poorly educated, and all were irregular residents. As for the length of experience as a CSW, it varied from 1 month to 8 years; former and seasonal CSWs were also represented. The following categories emerged from the participants' discourses as the main reasons for leaving their home country and emigrating to Europe: low socioeconomic position at home; lack of prospects; and association of Europe with greater opportunities.

The participants explained that personal determinants such as poverty, little social support, difficulty with obtaining a residency permit, and the need to survive forced them to become CSWs. None of the informants mentioned previous experience as a CSW in Nigeria, where great stigma is attached to sex work. None declared being HIV positive.

The participant CSWs knew the risk of contracting STI/HIV when engaging in unprotected sex and they were aware that their trade implies a higher risk. They knew that condoms are essential in STI prevention and claimed to use them almost always with clients and 
sometimes with their partners. Participants also performed other preventive practices. The CSWs did not consider themselves a risk to their clients and were not concerned about their clients' safety.

The Nigerian CSWs in this study had a low educational level, had emigrated on their own and had worked on the streets. They were already living in adverse financial conditions in their home country. These results agree with those of Folch et al ${ }^{41}$ on prostitutes of African origin in Barcelona. The results also corroborate those obtained from Edo State, the region of Nigeria from which most of the participants came. ${ }^{32}$ Moreover, the 60 CSWs in the study of Muñoz et $a l^{33}$ also described adverse socioeconomic conditions since childhood (single-parent families and orphans).

It is essential to underscore socioeconomic status as a key factor related to cognitive function, work opportunities, income, behaviour and lifestyle, and health status throughout life. $^{34}$

The participants of this study showed good knowledge of STI, acquired through experience and advice from NGOs and others. Most of them had not received sex education in their home country, and only the participant with the highest educational level had precise knowledge on STI/HIV.

Studies carried out in West Africa (Benin) found a higher use of condoms and a significant reduction in the prevalence of STI/HIV in CSWs after the implementation of the AIDS 1/2/3 programme in Benin since 1992. ${ }^{6-9}$ This programme includes health education interventions, change of behaviour, and access to and adequate use of condoms.

The recent systematic review by Chersich et $a l^{18}$ shows that promotion of preventive behaviour, counselling, health education and easy access to genitourinary clinics contribute to reducing risky sex behaviour. Community and CSW empowerment are essential to reduce the risk of exposure to and infection with STI/HIV in this group. $^{16} 1819$

With regard to preventive behaviour, all participants asserted that they used condoms during intercourse with clients and sometimes with their partners if they refused to be screened for STI. These results agree with the above-mentioned study on the AIDS $1 / 2 / 3$ programme ${ }^{7-9}$ and other reports. ${ }^{5} 10{ }^{35}$ Understanding the effectiveness of condoms to prevent STI correlates with consistent use. ${ }^{36}$

Other preventive behaviours, such as use of handkerchiefs, saliva, water and medicinal products from Nigeria as disinfectants or treatments for STI or when a condom breaks, also agree with previous studies. ${ }^{17} 32$ This suggests that cultural traditions and traditional medicine have a significant role in the prevention of diseases including STIs. Many of these participants self-prescribe penicillin as a magic bullet, probably because it is the best known and most accessible antibiotic. ${ }^{17}$

The participants did not report any difficulty in accessing health services in Barcelona. All of them went for check-ups at some point, in particular at the start of a new relationship, to determine if they could have unprotected sex, as previously reported by del Romero $e t a l^{37}$ and Vall-Mayans et $a l^{88}$ in our setting. However, some participants explained that they do not always return for results in case they find they are infected. These results differ from those of Langa et al in Mozambique, ${ }^{10}$ where CSWs did not trust health professionals and did not often use available services. The participants of this study did not report problems in accessing social services and some received benefits for themselves or their children.

Access to health and social services, to diagnostic tests for STI and to prevention programmes are key prevention tools and a strength of our universal health system. However, it is essential to improve social conditions and to empower CSWs to effectively reduce exposure and infection risk of STI/HIV in this group.

In contrast with several articles that associate prostitution with drug and alcohol misuse, none of the participants in this study admitted to drug use. ${ }^{35} 39$

In agreement with other studies of Nigerian CSWs, ${ }^{17}$ all participants were aware that unprotected intercourse with clients was their main exposure risk factor for STI/ HIV. Also reported in Nigeria and other African settings, the use of condoms during intercourse with clients ${ }^{4} 68$ is much higher than during intercourse with their partners, ${ }^{8} 36$ which constitutes a significant risk behaviour for contracting STI/HIV.

On the other hand, the participants' discourses revealed that more and more clients are aware of the need to use condoms, in particular tourists. However, some clients still offer a premium to have unprotected sex, which can be an incentive for CSWs. Some studies conducted in African settings corroborate the trend for clients to use condoms during intercourse. ${ }^{40}$ However, the need to please clients, clients not accustomed to condoms, lack of money to pay the extra fee for the condom, or sometimes a dislike of them by the CSWs themselves are the most common explanations for not using this barrier method during intercourse. ${ }^{32}$

Despite the help of key informants (NGO personnel), we found several problems in recruiting CSWs (lack of time, willingness to discuss these issues, and not being financially incentivised to enrol in the study). Although some of these difficulties are known problems in the recruitment of immigrants, ${ }^{41}$ we cannot rule out the possibility that CSWs who refused to participate had experiences and sexual behaviours that were less socially acceptable than those CSWs who did agree to participate. Owing to recruitment problems, we could not carry out triangulation groups, and the methodological perspective proposed in the study protocol had to be changed without endangering the aim and reliability of the data generated ${ }^{30}{ }^{42}$ In addition, only women that spoke English or Spanish were invited to participate. However, neither language was the participant's mother tongue, which could have affected their discourse. 
In this respect, the use of semistructured interviews together with the dexterity of the interviewers managed to identify the most relevant issues on STI risk perception in Nigerian CSWs and to reach saturation with the eight completed interviews; the last few interviews did not provide new information on the study objective.

Although caution needs to be applied when transferring these results to other settings, our results generally agree with other studies in similar population groups.

This study contributes new data on the construction of the perception of contracting and transmitting STI among Nigerian CSWs, a highly visible group in the Raval of Barcelona.

The research group is multidisciplinary (psychology, public health, anthropology and nursing) and their reflexivity has contributed to decision making in all phases of this research.

All phases of the investigation have been described, and the study followed criteria of quality in qualitative research. In preparing the manuscript, we followed the Consolidated criteria for reporting qualitative research (COREQ) and the Qualitative research review guidelines. ${ }^{30} 424$

\section{Future areas of research}

The positive effects of comprehensive programmes focusing on vulnerable populations, such as the AIDS $1 / 2 / 3$ carried out in Benin, prove the need to maintain and prioritise such initiatives. The findings of the present study should contribute to programmes aimed at CSWs. Other aspects such as cultural determinants, beliefs and rites should be investigated, since they influence decision making with regard to STI/HIV prevention in CSWs.

When designing intervention programmes, it is necessary to consider the knowledge provided by qualitative studies that explore the beliefs and habits of the study population. Analysing these beliefs and habits in depth, as well as the cultural aspects and knowledge of the study population, is essential for designing more acceptable, adapted, appropriate and feasible interventions.

All the participants in this study stated that they would engage in different work if they had the opportunity. Therefore, with improved integration of these women into the host society and greater access to other employment opportunities, they would not need to work as CSWs.

\section{Conclusions}

This study confirms that Nigerian CSWs who work in the Raval district of Barcelona live in adverse socioeconomic conditions, have little social support and are illegal residents, and they only resort to sex work as a means of survival. These personal determinants, together with their condition as immigrants (experiences and practices in the home and host countries), influence the construction of risk perception of STI/HIV and their preventive behaviour with regard to sex. The perception of risk is based on various elements shown in figure 2. Our informants consider that their occupation involves a high risk of contracting STI/HIV and acknowledge use of condoms with clients as the main preventive measure. However, their perception of risk decreases when they consider intercourse with their partners. We should underscore that they do not consider themselves a factor in dissemination of STIs.

Despite their knowledge on mechanisms of transmission of STI/HIV and their use of condoms with clients, gaps and conceptual errors on prevention still exist-for instance, when they choose not to use a condom during intercourse with their partner. All these factors must be taken into account in the design of preventive programmes aimed at vulnerable populations such as CSWs.

Acknowledgements We thank the women who agreed to participate. We also thank Inés Clares from El Iloc de la dona for her cooperation in recruitment of study participants and Dr Martí Vall for his contributions to the study. We would like to thank the IDIAP Jordi Gol for the translation of this manuscript into English.

Contributors NCA, CM-L, ABO and EP-R contributed to the protocol, the interview schedule and the analysis. NCA and CM-L made the transcriptions. NCA, CM-L, ABO and EP-R drafted the manuscript and approved the final version.

Funding This study was supported by Projecte XB of the Àmbit d'Atenció Primària Barcelona Ciutat (Institut Català de la Salut).

Competing interests None declared.

Patient consent Obtained.

Ethics approval The study protocol has been approved by Clinical Research Ethics Committee (CEIC) of the IDIAP Jordi Gol (Barcelona)(P12/038).

Provenance and peer review Not commissioned; externally peer reviewed.

Data sharing statement No additional data are available.

Open Access This is an Open Access article distributed in accordance with the Creative Commons Attribution Non Commercial (CC BY-NC 4.0) license, which permits others to distribute, remix, adapt, build upon this work noncommercially, and license their derivative works on different terms, provided the original work is properly cited and the use is non-commercial. See: http:// creativecommons.org/licenses/by-nc/4.0/

\section{REFERENCES}

1. UNAIDS JUNPoHA. Global report: UNAIDS report on the global AIDS epidemic 2013. Contract No.: ISBN 978-92-9253-032-7.

2. Platt L, Grenfell P, Fletcher A, et al. Systematic review examining differences in HIV, sexually transmitted infections and health-related harms between migrant and non-migrant female sex workers. Sex Transm Infect 2013;89:311-19.

3. Belza MJ, Clavo P, Ballesteros J, et al. Social and work conditions, risk behavior and prevalence of sexually transmitted diseases among female immigrant prostitutes in Madrid (Spain). Gac Sanit 2004;18:177-83.

4. Folch C, Esteve A, Sanclemente C, et al. Prevalence of human immunodeficiency virus, Chlamydia trachomatis, and Neisseria gonorrhoeae and risk factors for sexually transmitted infections among immigrant female sex workers in Catalonia, Spain. Sex Transm Dis 2008;35:178-83.

5. Syvertsen JL, Robertson AM, Rolon ML, et al. "Eyes that don't see, heart that doesn't feel": coping with sex work in intimate relationships and its implications for HIV/STI prevention. Soc Sci Med 2013;87:1-8.

6. Alary M, Mukenge-Tshibaka L, Bernier F, et al. Decline in the prevalence of HIV and sexually transmitted diseases among female sex workers in Cotonou, Benin, 1993-1999. AIDS 2002;16:463-70.

7. Behanzin L, Diabate S, Minani I, et al. Decline in the prevalence of HIV and sexually transmitted infections among female sex workers 
in Benin over 15 years of targeted interventions 15. J Acquir Immune Defic Syndr 2013;63:126-34.

8. Eluwa Gl, Strathdee SA, Adebajo SB, et al. Sexual risk behaviors and HIV among female sex workers in Nigeria. J Acquir Immune Defic Syndr 2012;61:507-14.

9. Williams JR, Alary M, Lowndes CM, et al. Positive impact of increases in condom use among female sex workers and clients in a medium HIV prevalence epidemic: modelling results from project SIDA1/2/3 in Cotonou, Benin. PLoS ONE 2014;9:e102643.

10. Langa J, Sousa C, Sidat M, et al. HIV risk perception and behavior among sex workers in three major urban centers of Mozambique. PLOS ONE 2014;9:e94838

11. Safika I, Levy JA, Johnson TP. Sex work venue and condom use among female sex workers in Senggigi, Indonesia. Cult Health Sex 2013;15:598-613.

12. Maher L, Mooney-Somers J, Phlong P, et al. Condom negotiation across different relationship types by young women engaged in sex work in Phnom Penh, Cambodia. Glob Public Health 2013;8:270-83.

13. Osoba AO. Sexually transmitted diseases in tropical Africa. A review of the present situation. Br J Vener Dis 1981;57:89-94.

14. Rotimi VO, Somorin AO. Sexually transmitted diseases in clinic patients in Lagos. Br J Vener Dis 1980;56:54-6.

15. Sogbetun $A O$, Alausa $\mathrm{KO}$, Osoba $\mathrm{AO}$. Sexually transmitted diseases in Ibadan, Nigeria. Br J Vener Dis 1977;53:155-60.

16. Rekart ML. Sex-work harm reduction. Lancet 2005;366:2123-34.

17. Lawan UM, Abubakar S, Ahmed A. Risk perceptions, prevention and treatment seeking for sexually transmitted infections and HIV/AIDS among female sex workers in Kano, Nigeria. Afr J Reprod Health 2012;16:61-7.

18. Chersich MF, Luchters S, Ntaganira I, et al. Priority interventions to reduce HIV transmission in sex work settings in sub-Saharan Africa and delivery of these services. J Int AIDS Soc 2013;16:17980.

19. Luchters S, Chersich MF, Rinyiru A, et al. Impact of five years of peer-mediated interventions on sexual behavior and sexually transmitted infections among female sex workers in Mombasa, Kenya. BMC Public Health 2008;8:143.

20. Barri el Raval Districte de Ciutat Vella. Dades estadístiques. [homepage on the Internet]. Barcelona: Ajuntament de Barcelona: 2012 (cited 12 April 2015). http://lameva.barcelona.cat/ciutatvella/ca/ home/el-barri-del-raval

21. Brosa Hernández J. Representación de la prostitución inmigrante en la prensa. El caso de las prostitutas del barrio del Raval de Barcelona. Estudios sobre el Mensaje Periodístico 2012;18:259-73.

22. Guillé Tomás M. Fundamentación sobre la prostitución y una aproximación al barrio del Raval. ReiDoCrea. Revista electrónica de investigación y Docencia Creativa 2014;3:114-26.

23. Reeves S, Albert M, Kuper A, et al. Why use theories in qualitative research? BMJ 2008;337:a949.

24. Tuckett AG. Qualitative research sampling: the very real complexities. Nurse Res 2004:12:47-61.

25. Mason M. Sample Size and Saturation in PhD Studies Using Qualitative Interviews [63 paragraphs]. Forum Qual Sozialforschung/ Forum: Qual Soc Res 2010;11(3), Art. 8. http://nbn-resolving.de/urn: nbn:de:0114-fqs 100387

26. Conde F. Los grupos triangulares como espacios transicionales para la producción discursiva: un estudio sobre la vivienda en Huelva.
En: Gordo AJ y Serrano A, coordi. Estrategias y prácticas cualitativas de investigación social. $1^{\text {a }}$ ed. Madrid: Ediciones Pearson Prentice-Hall; 2008:155-87.

27. Coma AN, Mejia-Lancheros C, Berenguera A, et al. Risk perception of sexually transmitted infections and HIV in Nigerian commercial sex workers living in Barcelona: a study protocol. BMJ Open 2013;3:4

28. Burla L, Knierim B, Barth J, et al. From text to codings: intercoder reliability assessment in qualitative content analysis. Nurs Res 2008;57:113-17.

29. MacLean LM, Meyer M, Estable A. Improving accuracy of transcripts in qualitative research. Qual Health Res 2004;14:113-23.

30. Barbour RS. Checklists for improving rigour in qualitative research: a case of the tail wagging the dog? BMJ 2001;322:1115-17.

31. Folch $C$, Lazar $C$, Ferrer $L$, et al. Female sex workers and access to social and health services in Catalonia: Influence of region of origin and place of work. AIDS Care 2013;25:1033-8.

32. Asowa-Omorodion FI. Sexual and health behaviour of commercial sex workers in Benin City, Edo State, Nigeria. Health Care Women Int 2000;21:335-45.

33. Munoz J, Adedimeji A, Alawode O. 'They bring AIDS to us and say we give it to them': Socio-structural context of female sex workers' vulnerability to HIV infection in Ibadan, Nigeria. SAHARA J 2010;7:52-61.

34. Galobardes B, Shaw M, Lawlor DA, et al. Indicators of socioeconomic position (part 1). J Epidemiol Community Health 2006;60:7-12.

35. Syvertsen JL, Robertson AM, Palinkas LA, et al. 'Where sex ends and emotions begin': love and HIV risk among female sex workers and their intimate, non-commercial partners along the Mexico-US border. Cult Health Sex 2013;15:540-54.

36. Kayembe PK, Mapatano MA, Busangu AF, et al. Determinants of consistent condom use among female commercial sex workers in the Democratic Republic of Congo: implications for interventions. Sex Transm Infect 2008;84:202-6

37. del Romero GJ, Rojas CD, Ballesteros MJ, et al. Prostitución: un colectivo de riesgo. JANO 2004; LXVII.

38. Vall-Mayans M, Villa M, Saravanya M, et al. Sexually transmitted Chlamydia trachomatis, Neisseria gonorrhoeae, and HIV-1 infections in two at-risk populations in Barcelona: female street prostitutes and STI clinic attendees. Int J Infect Dis 2007;11:115-122.

39. Jeal N, Salisbury C, Turner K. The multiplicity and interdependency of factors influencing the health of street-based sex workers: a qualitative study. Sex Transm Infect 2008;84:381-5.

40. Lowndes CM, Alary M, Labbe AC, et al. Interventions among male clients of female sex workers in Benin, West Africa: an essential component of targeted HIV preventive interventions. Sex Transm Infect 2007:83:577-81.

41. Pons-Vigues M, Puigpinos R, Rodriguez D, et al. Strategies to recruit immigrant women to participate in qualitative research. Gac Sanit 2009;23(Suppl 1):90-2.

42. Tong A, Sainsbury P, Craig J. Consolidated criteria for reporting qualitative research (COREQ): a 32-item checklist for interviews and focus groups. Int J Qual Health Care 2007;19:349-57.

43. Kuper A, Lingard L, Levinson W. Critically appraising qualitative research. BMJ 2008;337:a1035. 